\title{
Brucella abortus strain 2308 putative glucose and galactose transporter gene: cloning and characterization
}

\author{
Richard C. Essenberg, Chris Candlerf and S. Kay Nidał \\ Author for correspondence: Richard C. Essenberg. Tel: +1 405744 6193. Fax: +1 4057447799. \\ e-mail: ressenberg@bmb.okstate.edu
}

Department of

Biochemistry and

Molecular Biology,

Oklahoma State University,

Stillwater, OK 74078, USA

\begin{abstract}
The gene for the putative transporter for glucose and galactose from Brucella abortus strain 2308 was isolated by functional complementation of Escherichia coli strains lacking either glucose or galactose transport systems. The same two plasmid clones were isolated from each screen. These clones restored glucose and galactose transport to the respective $E$. coli strains. The sequence of the 1806 bp overlap between these two plasmids was determined. A 1242 bp ORF whose disruption eliminated complementation of both E. coli strains showed $36 \%$ identity with the $E$. coli fucP gene encoding a fucose transporter. These two transporters are members of the major facilitator superfamily, in which they represent a previously undescribed family. In addition, an incomplete gene similar to $E$. coli hisG was found. One of the plasmids complemented $E$. coli hisG mutants.
\end{abstract}

Keywords: Brucella abortus, transport, glucose, galactose, major facilitator family

\section{INTRODUCTION}

Brucella abortus is a facultative intracellular pathogen capable of surviving and growing in macrophages and other professional phagocytes. It has been reported to grow on or oxidize many sugars, including glucose, galactose and fructose (McCullough \& Beal, 1951). Studies (Robertson \& McCullough, 1968a,b) indicated that glucose was metabolized by the hexose monophosphate shunt, then the tricarboxylic acid cycle. Presumably, related sugars, such as galactose and fructose, are converted to intermediates in the glucose pathway for further metabolism. An obligate aerobe such as $B$. abortus is expected to transport glucose and other sugars by some system other than the phosphotransferase system. This was demonstrated by Rest $\&$ Robertson (1974) for glucose. No phosphorylation of glucose was observed using phosphoenolpyruvate as a phosphate donor. Transport was sensitive to various inhibitors, suggesting a proton-coupled transport system. Though B. abortus can grow and multiply in macrophages and other phagocytic cells, it does not

†Present address: 4605 Sycamore Lane, Edmond, OK 73034, USA.

¥Present address : Department of Pediatrics, Oklahoma University Health Sciences Center, Oklahoma City, OK 73104, USA.

Abbreviation: MFS, major facilitator superfamily.

The GenBank accession number for the sequence reported in this paper is U43785. escape from the phagosome. Thus, bacteria must be able to obtain nutrients through the phagosome membrane.

We set out to isolate the gene for the glucose transporter in the hope that characterization of its transport properties might shed some light on how Brucella cells obtain nutrients in macrophages. In the course of characterizing this gene, we have determined that the same transporter can carry both glucose and galactose. We have also identified the Brucella hisG gene.

\section{METHODS}

Bacterial strains and plasmids. Virulent $B$. abortus strain 2308 was obtained from the Oklahoma Animal Disease Diagnostic Laboratory. Escherichia coli strains are listed in Table 1.

Growth media and general procedures. E. coli strains were routinely grown on Luria Broth (LB) (Luria \& Burrous, 1957). E. coli cells were transformed by a method involving polyethylene glycol (Chung et al., 1989) unless very high efficiency was required, in which case the method of Hanahan (1983) was used. Restriction endonucleases were used under the conditions suggested by their manufacturers. Utilization of glucose and galactose was determined using MacConkey agar or eosin-methylene blue agar (Difco) with the desired carbohydrate at $50 \mathrm{mM}$. Growth on minimal medium was evaluated on medium A (Miller, 1972) with carbon sources at $10 \mathrm{mM}$ and other supplements added as necessary. Ampicillin was used at $50 \mu \mathrm{g} \mathrm{ml}^{-1}$. B. abortus strains were grown on tryptose agar (Difco) at $37^{\circ} \mathrm{C}$ in $5 \% \mathrm{CO}_{2}$. Fragments from restriction enzyme digests of plasmids were purified on low-melting- 
Table 1. Strains used in this study

\begin{tabular}{|c|c|c|}
\hline Strain & Genotype & Source or reference \\
\hline RE507 & $\mathrm{Hfr}(\mathrm{PO} 45)$ relA1 spoT1 thi-1 $\Delta(\mathrm{rec} A-s r l R) 306$ srlR301::Tn10-84 & Essenberg \& Sharma (1993) \\
\hline PPA42 & $\mathrm{Hfr}(\mathrm{PO} 45)$ thi $\Delta(p t s-c r r)$ galP & P. Postma, Amsterdam \\
\hline RE707 & As PPA42, but gyrA $\Delta(r e c A-s r l R) 306 s r l R 301:: \operatorname{Tn} 10-84$ & $\begin{array}{l}\text { RE507 } \times \text { spontaneous } \mathrm{Nal}^{\mathrm{r}} \text { derivative of } \\
\text { PPA42, selected for } \mathrm{Tc}^{\mathrm{r}} \text { and } \mathrm{Nal}\end{array}$ \\
\hline JM2071 & bis leu ilv $\Delta$ lac mglP galP:: Tn10 & CGSC 6902 \\
\hline RE659 & bis leu ilv $\Delta l a c$ mglP $\Delta$ galP & $\begin{array}{l}\text { JM2071 selected for } \mathrm{Tc}^{\mathrm{s}} ; \text { Maloy } \& \\
\text { Nunn (1981) }\end{array}$ \\
\hline RE777 & As RE659, but $\Delta(r e c A-s r l R) 306 s r l R 301:: \operatorname{Tn} 10-84$ & RE507 $\times$ RE659, selected for $T c^{r}$ \\
\hline AT2681 & $\begin{array}{l}\text { bisG1 purF1 glyA6 argH1 thi-1 lacY1 or Z4 malA1 xyl-7 mtl-2 } \\
\text { rpsL8, } 9 \text { or } 14 \text { supE44 }\end{array}$ & CGSC 4521 \\
\hline JF4279 & As AT2681, but malA ${ }^{+}$ & AT2681, spontaneous $\mathrm{mal}^{+}$ \\
\hline RE518 & As JF4279, but $\Delta(r e c A-s r l R) 306 s r l R 301:: \operatorname{Tn} 10-84$ & RE507 $\times$ JF4279, selected $\mathrm{Tc}^{\mathrm{r}}$ \\
\hline JC10289 & $\begin{array}{l}\text { thr-1 leuB6 proA2 hisG4 } \Delta(r e c A-s r l R) 306 \text { srlR301::Tn10-84 argE3 thi-1 } \\
\text { ara-14 lacY1 galK2 xyl-5 mtl-1 rpsL31 tsx33 supE44 }\end{array}$ & $\begin{array}{l}\text { R. D. Porter, Penn State University } \\
\text { Csonka \& Clark (1979) }\end{array}$ \\
\hline
\end{tabular}

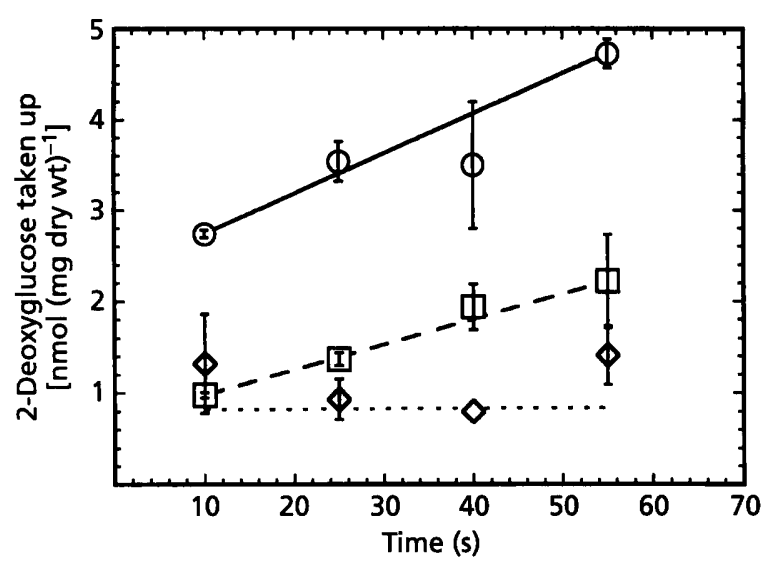

Fig. 1. 2-Deoxyglucose transport by RE707 carrying pBluescript KS $(\diamond)$, pRE168 $(O)$ and pRE169 ( $\square)$. Error bars show the SEM for three determinations.

point agarose and extracted using diatomaceous earth (Carter \& Milton, 1993). The inserts in plasmids pRE183 and 184 were progressively shortened from the SacI end using exonuclease III and mung bean nuclease (Heinrich, 1988). Plasmids were extracted from individual transformants and digested with $B g l I$ to determine the extent of the deletion.

Construction of the B. abortus strain 2308 library. A fully representative $B$. abortus genomic library was constructed in the vector $\lambda$ ZAP II (Stratagene) with fragments of $5-8 \mathrm{~kb}$ produced by a partial Sau3A digestion of the chromosomal DNA of the virulent $B$. abortus strain 2308 inserted into the $X$ XoI site of the vector, following the protocols of the manufacturer. The library consisted of 7750 plaques, of which $3 \%$ had no insert. The 7517 clones is about three times the 2400 necessary for a $99 \%$ probability for any $B$. abortus gene to be represented in a recombinant phage (Clark \& Carbon, 1979), using the $B$. abortus genome size of $2600 \mathrm{~kb}$ (AllardetServent et al., 1988). The library was amplified in E. coli strain XL1-Blue as $\lambda$ ZAP II plaques (Bullock et al., 1987). Several multiples of the library were produced as the single-stranded
pBluescript phagemid packaged as a filamentous phage particle by co-infecting XL1-Blue cells with the $\lambda$ ZAP II phage library and the helper phage R408. Greater multiples of the single-stranded library were converted to the plasmid vector pBluescript, which is designated as pSK- by Stratagene.

Transport assays. Transport was assayed in washed cell suspensions at room temperature after growth in LB to late exponential phase. Cells were washed twice in medium A and resuspended in 0.5 vols medium $A$. Glucose transport was assessed using 2-[G- $\left.{ }^{3} \mathrm{H}\right]$ deoxyglucose (specific activity $1 \mathrm{MBq}$ $\mu \mathrm{mol}^{-1}$; ICN). Galactose transport was assessed using [U$\left.{ }^{14} \mathrm{C}\right]$ galactose (specific activity $0.37 \mathrm{MBq} \mu \mathrm{mol}^{-1}$; ICN). Reactions were started by adding radioactive substrate to the cell suspension to $0.5 \mathrm{mM}$. Samples were removed and filtered through $0.45 \mu \mathrm{m}$ membrane filters (Gelman) at various times thereafter. Filters were washed with $2 \mathrm{ml}$ medium A, then the cells lysed with $0.2 \mathrm{ml} 1 \%$ SDS. Released radioactivity was counted in $5 \mathrm{ml}$ Instagel (Packard Instrument Co.). The density of the cell suspension was determined by $\mathrm{OD}_{680}$ in a $1 \mathrm{~cm}$ cuvette in a Gilford model 240 spectrophotometer. This value was converted to dry weight using the relationship $\mathrm{OD}_{680}$ of 1 equals $0.68 \mathrm{mg}$ dry wt $\mathrm{ml}^{-1}$ (Kay \& Kornberg, 1971). Rates of transport were taken as the gradient of the best fit straight line through the data points.

Nucleic acid hybridization. Restriction enzyme digests of plasmids were electrophoresed on agarose gels, then transferred to nitrocellulose (BA85, Schleicher \& Schuell) by capillary transfer (Southern, 1975). Conditions for hybridization were as suggested by the manufacturer of the nitrocellulose (Schleicher \& Schuell, 1987). The probe was isolated from low-melting-point agarose using diatomaceous earth (Carter \& Milton, 1993) after digestion and electrophoresis to separate the insert from the vector. The probe was labelled with biotin using the random priming method with half the dTTP replaced with bio-11-dUTP (Sigma). Hybridization was in $50 \%(\mathrm{v} / \mathrm{v})$ formamide, $6 \times \operatorname{SSPE}(1 \times$ SSPE is $0 \cdot 18 \mathrm{M} \mathrm{NaCl}, 0 \cdot 01 \mathrm{M} \mathrm{NaPO}_{4}, \mathrm{pH} \mathrm{7.7,1} \mathrm{mM}$ EDTA) at $42^{\circ} \mathrm{C}$, with a final wash in $0 \cdot 16 \times \mathrm{SSPE}$ at $65^{\circ} \mathrm{C}$. Hybridizing bands were visualized with the BluGene kit (BRL).

Nucleotide sequencing. Plasmids to be sequenced were transformed into XL1-Blue, then purified using a Magic or Wizard kit (Promega). Sequences were determined either by 
the dideoxy nucleotide chain-termination method (Sanger $e t$ al., 1977) using Sequenase version 2.0 (USB) or by cycle sequencing by the Oklahoma State University (OSU) Recombinant DNA/Protein Resource Facility. Sequenase reactions were electrophoresed on a $60 \mathrm{~cm}$ gel in a Base Runner (IBI) using $5 \%$ Long Ranger (AT Biochem) gels. Cycle sequences were read in an ABI Model 373A Sequencer. Gaps remaining in the sequence were filled in using primers designed from the known sequence and synthesized by the OSU Recombinant DNA/Protein Resource Facility.

Sequences were assembled using the GCG programs (Devereux et al., 1984). ORFs were found using MacVector (IBI) and Ecoparse (Krogh et al., 1994). The GenBank, PDB, SWISS-PROT and PIR databases were searched using BLAST (Altschul et al., 1990) at NCBI or FASTA (Pearson \& Lipman, 1988) through the GCG package. Sequences were aligned using the PILEUP program in the GCG package. Significance scores for these alignments were calculated with the program MalSig (Melcher, 1993), using the PAM256 matrix (Dayhoff $e t$ al., 1983) and 30 scrambled sequences. The multiple alignment from PILEUP was refined using the CLUSTAL $w$ program. Phylogeny was calculated by the PHYLIP package (Felsenstein, 1989) using distances and the FITCH algorithm.

\section{RESULTS}

\section{Cloning the gene for the glucose transporter}

E. coli strain RE707 is unable to transport and grow on glucose as sole carbon source because it is deleted for several enzymes of the phosphotransferase system and is defective in the galP system which can also transport glucose if induced or constitutively mutated. A B. abortus 2308 plasmid library was transformed into strain RE707 and plated on several different indicator media containing glucose and on glucose minimal medium. Each medium produced about an equal fraction of colonies (about 1 in 1000 transformants) that appeared different from the vector control (or grew, in the case of minimal medium). Several of these were picked and further tested on other indicator media, and also on mannitol MacConkey medium to see if the phosphotransferase system deficiency was complemented. No mannitol-utilizing strains were found. Strains positive for glucose on any of the media were also positive on the other media. The colour of these strains on the indicator media was definitely different from that of the vector-only strains, but much less intense than that of the wild-type strain. When plasmids were extracted from several positive strains and used to re-transform strain RE707, some, but not all, were found to complement in the second round. Plasmids were extracted from strains that showed complementation in the second round and digested with BglI. Most showed the same pattern of fragments: a representative, pRE168, was chosen. One, whose phenotype appeared somewhat less positive, had a different pattern and was designated pRE169. RE707 transformants carrying pRE168 showed a significantly higher rate of 2deoxyglucose transport than those carrying the vector alone (Fig. 1). The rate for pRE169 transformants was less than for pRE168 transformants but greater than that with vector alone, though not significantly greater.

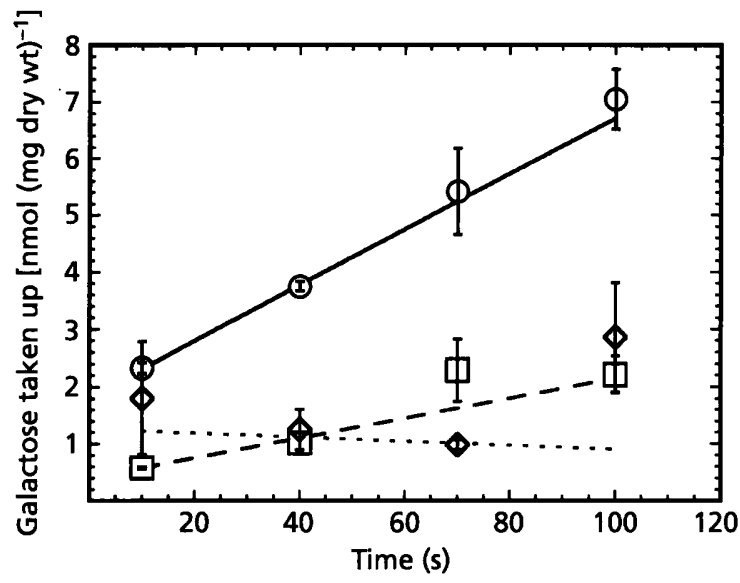

Fig. 2. Galactose transport by RE777 carrying no plasmid $(\diamond)$, pRE183 (O) and pRE184 ( $\square)$. Error bars show the SEM for three determinations.

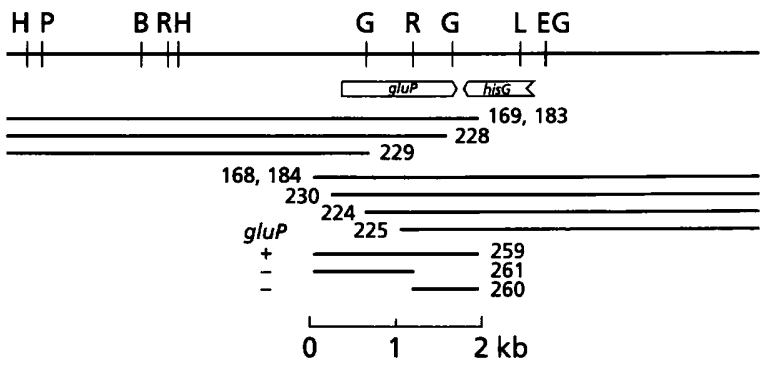

Fig. 3. Restriction map of the $B$. abortus DNA contained in the glucose- and galactose-complementing clones. The top line shows sites of digestion by BamHI (B), ECoRI (E), Bg/l (G), HindIII (H), Sall (L), Pstl (P) and Rsal (R). Not all Bg/l sites in pRE168/184 have been mapped. Below the locations of the ORFs encoding the transporter (g/uP) and hisG are shown. The arrows indicate the direction of transcription. The $5^{\prime}$ end of his $G$ is not located. The lower set of lines shows the extent of the DNA contained in the original plasmids, exonuclease III-generated deletions of them and the clones of the overlap region. For the subclones, the ability to $(+)$ or not to $(-)$ complement glucose or galactose transport is indicated.

\section{Cloning the gene for the galactose transporter}

E. coli strain RE777 is mutated in all three transport systems (lacY, $m g l P$, galP) that can transport galactose and so is unable to utilize or grow on galactose. The galactose transporter gene from $B$. abortus was isolated in a manner similar to that used for the glucose transporter, using complementation of RE777. Recombinant clones that were positive on galactose MacConkey medium were also positive on galactose minimal medium and vice versa. The red colour on MacConkey medium or growth on minimal medium in this case was about the same as for wild-type $E$. coli. Plasmids that gave a galactose-positive phenotype on retransforming RE777 were digested with $B g l \mathrm{I}$, and again fell into two types, designated pRE183 and pRE184. Galactose transport by RE777 carrying pRE184 showed 
1 TCGACCTCGA TCQACOCCAO ACGCGGTTGA CCACCAGITC TGGACTICCC CACAAAAAGC CGTGCCAAAA TGCGCBOCTT TITCATAITT CACATGACTG

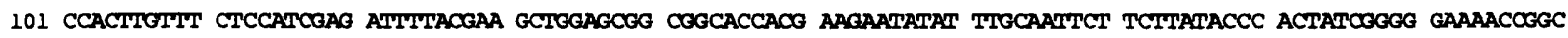
201 TGACAACGTC CTGAAGGAIT GCATAGCGAT ATCITGTGAG ATPAGGCAGC CCCCACIIIT GACGCAAGCT CCGGCCCACC GTCGCATCTT GIAATAATIT

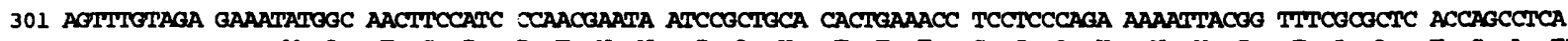
$\begin{array}{lllllllllllllllllllllllllllllll}M & A & T & S & I & D & T & N & N & P & L & H & T & E & T & S & S & Q & K & N & Y & G & F & A & L & T & S & L & T\end{array}$ 401 CCTTGCTGT TITCATGTG GGCTTCATCA CCTGTCTCAA CGACATCCTG ATCCOGCATC TAAAGAACGT TMTCCAGCTC AACTAICACCC AGTCGATGCT

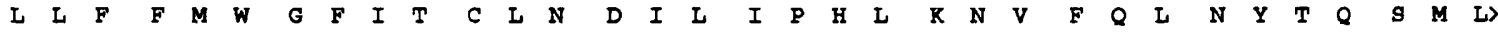

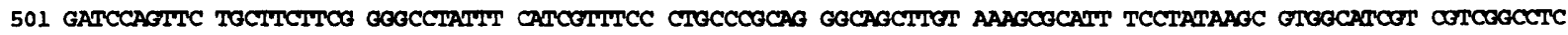
$\begin{array}{lllllllllllllllllllllllllllllllllll}I & Q & F & C & F & F & G & A & Y & F & I & V & S & L & P & A & G & Q & L & V & K & R & I & S & Y & K & R & G & I & V & V & G & L\end{array}$

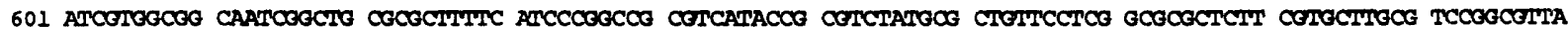
$\begin{array}{llllllllllllllllllllllllllllllllllll}I & V & A & A & I & G & C & A & L & F & I & P & A & A & S & Y & R & V & Y & A & L & F & I & G & A & L & F & V & L & A & G & G & V & T\end{array}$

701 CGATCCTTCA GGTTGCCGCC AATCCCTATG TGACGATCCT TOGCAAGCCT GAAACCGCOG CAAGCOGCCT GACACTGACA CACGCCIPCA ACTCGCTLGG $\begin{array}{lllllllllllllllllllllllllllllllllllll}I & L & Q & V & A & A & N & P & Y & V & T & I & L & G & K & P & E & T & A & A & S & R & L & T & L & T & Q & A & P & N & S & L & G\end{array}$

801 CACCACBOTT GCGCCGOTCT TPIGGCOCAGT OCTGATCCTP TCAGCGGCAA COGACGCCAC COTCAATGCC GAAGCCGACG CGGITCGCIT CCCATATCIT

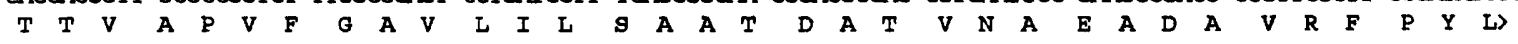

901 CITCTOGCGC TTGCCTTCAC GGTHCTHOCC ATCATCTITO CAATCCTGAA ACOGCCGGAT GTGCAGGAAG ACGAACCCGC CCTITCCGAC AAGAAAGAGG $\begin{array}{lllllllllllllllllllllllllllllllllllll}\text { L } & L & A & L & A & F & T & V & L & A & I & I & F & A & I & L & K & P & P & D & V & Q & E & D & E & P & A & L & S & D & K & K & E & G)\end{array}$

1001 GCAGCGCCTG GCAATATCOC CACCTOGTTC TGGGAGCGAT COOCATHPTC GTOTACOTCO GCGCTGAGGT CAGCGTCGGC AGCTTCCTCG TGAATHTCCT $\begin{array}{llllllllllllllllllllllllllllllllllll}S & A & W & Q & Y & R & H & L & V & L & G & A & I & G & I & F & V & Y & V & G & A & E & V & S & V & G & S & F & L & V & N & F & L>\end{array}$

1101 GAGCGATCCC ACCGTTGCTO GCCTCTCCGA AACCGAOGCC GCCCATCACO TOGCCTAIPT CTOGGGOOGG GACATGOTOG GCOOCTTCAT COGCTCOGCA $\begin{array}{llllllllllllllllllllllllllllllllll} & S & D & P & T & V & A & G & L & S & E & T & D & A & A & H & H & V & A & Y & F & \text { W } & G & G & D & M & V & G & R & F & I & G & S & A\end{array}$

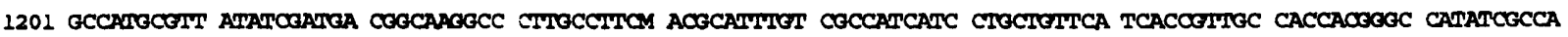

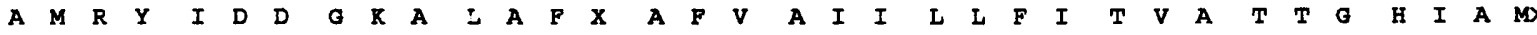

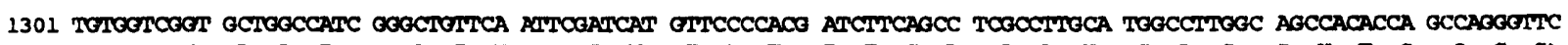

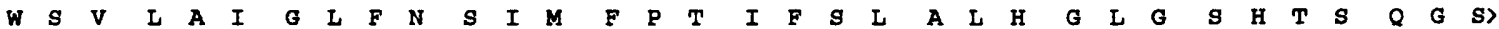

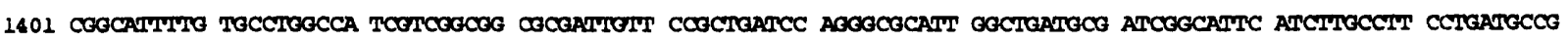
$\begin{array}{lllllllllllllllllllllllllllllllllll}G & I & L & C & \text { L } & A & I & V & G & G & A & I & V & P & \text { L } & I & Q & G & A & \text { L } & \text { A } & \text { D } & \text { A } & \text { I } & G & \text { I } & \text { H } & \text { L } & \text { A } & F & \text { L } & M & \text { P) }\end{array}$

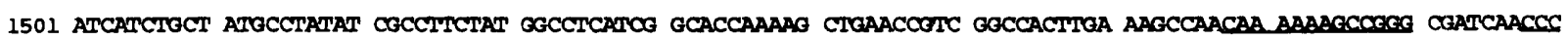
$\begin{array}{lllllllllllllllllll}I & I & C & Y & A & Y & I & A & F & Y & G & L & I & G & T & K & \text { S) }\end{array}$

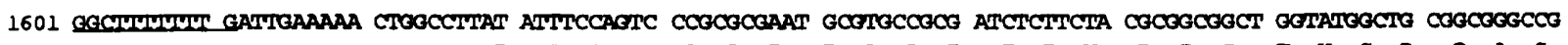
$\begin{array}{llllllllllllllllllllllllll}I & E & L & G & A & R & I & R & A & A & I & E & E & V & R & R & S & T & H & S & R & R & A & S\end{array}$

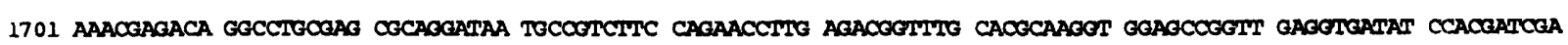
$\begin{array}{lllllllllllllllllllllllllllllllllllll} & V & L & C & A & Q & S & R & L & I & I & G & D & E & L & V & K & L & R & N & A & R & L & T & S & G & T & S & T & I & D & V & I & S\end{array}$

1801 GOTCGA

$\langle T \mathbf{S}$

Fig. 4. Nucleotide sequence of the insert of pRE259. This sequence is in the same orientation as Fig. 3. The predicted amino acid sequence $(\mathrm{N}-\mathrm{C})$ of the glucose transporter is shown under the nucleotide sequence followed by a portion of the His protein (C-N). A possible stem-loop structure is underlined.

a significantly higher rate than RE777 with vector alone (Fig. 2). The rate for pRE183 transformants was higher than for RE777 with vector alone, but again, not significantly higher.

\section{Identity of the glucose and galactose transporter clones}

pRE168, 169, 183 and 184 were mapped with restriction enzymes (Fig. 3). pRE168 and 184 were apparently identical, as were pRE169 and 183. The inserts from the galactose clones pRE183 and 184 were isolated and labelled with biotin and used to probe $B g l \mathrm{I}$ and $R s a \mathrm{I}$ digests of the glucose-complementing clones pRE168 and 169. pRE183 and 169 hybridized completely, as did pRE184 and 168. pRE183 also hybridized with some, but not all, bands of pRE168 as did pRE184 with pRE169. Subclones complementing glucose transport also complemented galactose transport and vice versa.

\section{Location of the transporter gene}

On the basis of restriction mapping, it was difficult to determine the overlap of the two kinds of plasmids, since few restriction sites or fragments were common to both. Initial re-cloning experiments and crosshybridization demonstrated that the overlap was over about a third of each insert. The single $R s a$ I site in the insert of pRE184 and two $B g l \mathrm{I}$ sites (giving a $1 \mathrm{~kb}$ fragment) are in this area (Fig. 3). Plasmid pRE259, formed using fragments from $\mathrm{pRE} 183$ and 184 from the $R s a$ l site to the end of the insert in the shortest direction 


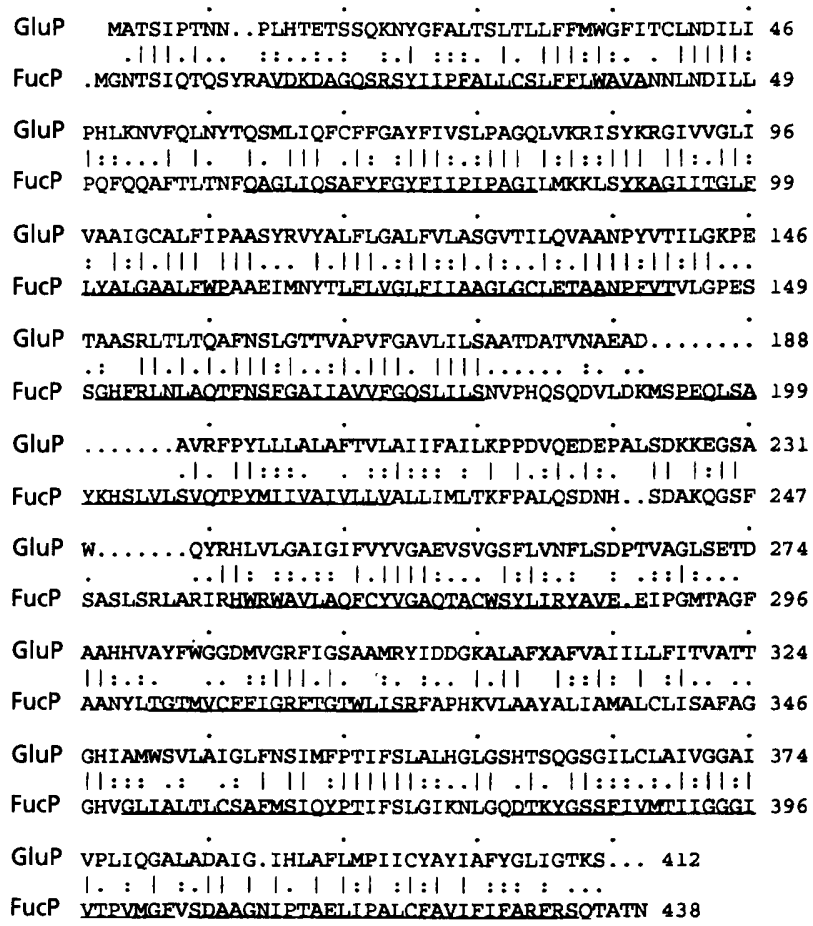

Fig. 5. Alignment of the putative glucose transporter protein (GluP) and the $E$. coli fucose transporter (FuCP, SWISS-PROT no. P11551). This alignment was done by the GCG program GAP. ' $I$ ' indicates identity, ' $\because$ ' indicates a score of $>0.5$ and '. indicates a score of $>0.1$, using a normalized PAM256 scoring matrix. Underlined segments are potential transmembrane helices, found with the TMAP program (Persson \& Argos, 1994) using an alignment of several sugar transporters.

and thus containing only the overlap between the two, complemented both RE707 and 777 as well as either pRE183 or 184 as detected by colour on MacConkey medium. Either of the fragments alone (pRE260 and 261) failed to complement as did all the exonuclease IIIgenerated deletions (Fig. 3).

\section{Nucleotide sequence of transporter region}

The nucleotide sequence of the $1806 \mathrm{bp}$ B. abortus DNA insert of subclone pRE259 was determined (Fig. 4). It has a major ORF from bp 316 to 1551 , encoding a protein of $44122 \mathrm{Da}$ with a $\mathrm{pI}$ of 6.87 . This protein is $58 \%$ similar ( $36 \%$ identical) to the fucose transporter of E. coli (Fig. 5). It shows several hydrophobic, potentially membrane-spanning regions typical of transporters (Fig. 6). Other proteins with significant similarity to this protein are a glucose transporter from trypanosomes and a vesicular acetylcholine transporter from mammals. There is no obvious promoter region, though the gene for this protein is probably expressed from its own promoter, since the original plasmids had inserts in both orientations with respect to the lac $Z$ promoter of the vector. There is no obvious Shine-Dalgarno sequence. A very large potential stem-loop structure is found starting $28 \mathrm{bp}$ beyond the end of the ORF. This

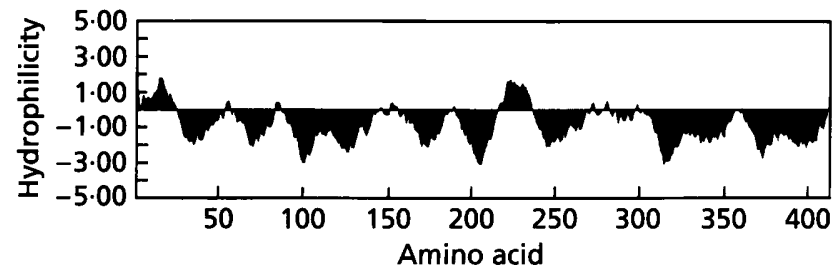

Fig. 6. Hydrophilicity plot of the putative glucose transporter of $B$. abortus determined using the MacVector program with the Kyte-Doolittle method and a window of 15 amino acids.

structure is very similar to one downstream of the fur gene of Vibrio anguillarum (GenBank no. L19717). Another potential ORF is found at the end of the insert, oriented in the opposite direction to the glucose transporter. This ORF encodes a part of a protein with similarity to the his $G$ protein of $E$. coli and Salmonella typhimurium.

\section{Similarity to other members of the major facilitator superfamily}

Both the Brucella glucose/galactose transporter and the E. coli fucP transporter show the 12 transmembrane segments typical of members of the major facilitator superfamily (MFS) (Griffith et al., 1992; Marger \& Saier, 1993), though one of the segments is not as prominent a hydrophobic feature as in some transporters. The sequences were aligned with each other and with representatives of the five MFS families and the significance of the alignments calculated (Table 2). All comparisons with the other families, except two, show scores of 6 or greater. For family 3, they are greater than 9 , strongly suggesting homology. The score for the alignment of the Brucella transporter with $f u c P$ is 24.37 , clearly showing homology. These two, and representatives of the other families were aligned and a

Table 2. Significance of alignment to representatives of MFS families

Scores are given as SD for the alignment compared to the mean of 30 permuted variants of the sequences using the MalSig program.

\begin{tabular}{|llr|}
\hline Family* & gluP & \multicolumn{1}{c|}{ fucP } \\
\hline 1 & 7.62 & 9.56 \\
2 & 4.70 & 5.48 \\
3 & 9.31 & 11.00 \\
4 & 6.52 & 8.87 \\
5 & 6.59 & 8.02 \\
\hline
\end{tabular}

* Representatives of the various families, obtained from the SWISS-PROT database are: 1, nora_staau, tcr3_ecoli; 2 , glf zymmo, xyle_ecoli, arae_ecoli, hup1_chlke, gtr2_mouse; 3, cit_klepn, ciu2_ecoli, kgtp_ecoli; 4, pgtp_salty, glpt_ecoli, uhpt_ecoli; 5, lacy_klepn, rafb_ecoli. 


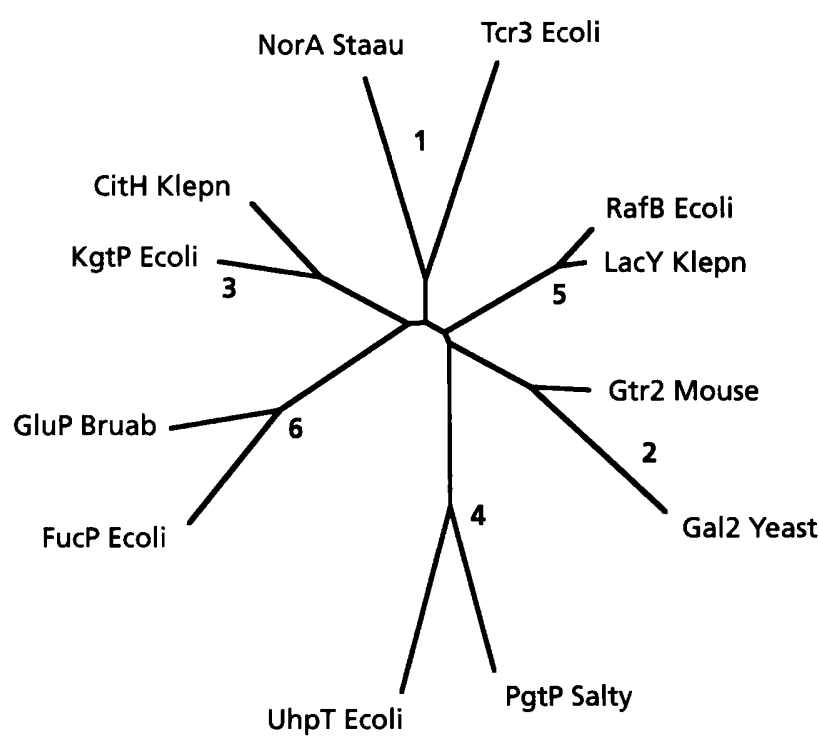

Fig. 7. Unrooted phylogenetic tree of selected members of the MFS, showing the relation of the $B$. abortus glucose/galactose transporter (GluP Bruab) and E. coli FucP (FucP Ecoli) to members of previously described families. Members are identified by locus names, and the numbers indicate the families defined by Marger \& Saier (1993), except for the new family 6 . Branch lengths are proportional to distance. Klepn, Klebsiella pneumoniae; Salty, Salmonella typhimurium; Staau, Staphylococcus aureus.

phylogeny determined (Fig. 7). These two form a new grouping on a branch about the same length as that for the other families.

\section{Complementation of hisG}

Plasmids pRE183 and pRE184 were transformed into E. coli strains RE518 and JC10289, both hisG. pRE184 but not pRE183 was able to complement both strains to histidine independence.

\section{DISCUSSION}

Plasmids pRE183 and 184 and subclone pRE259 all correct the inability of strain RE707 to use glucose and the inability of strain RE777 to use galactose. In addition, pRE168 restored glucose transport to strain RE707 and pRE184 restored galactose transport to strain RE777. pRE168 and 184 may give a higher rate of transport because they have the transporter gene oriented so its transcription could be driven by the vector's lac promoter, as well as the Brucella promoter. Since pRE169 and 183 also complement, the Brucella promoter must be active, though its activity may be low in E. coli. It is also possible that pRE169 and 183 carry genes that interfere with transport. Subclone pRE259 carries an ORF whose extent correlates with the ability of deletions to complement the E. coli strains. This ORF encodes a protein similar to the $E$. coli fucose transporter. Thus, these two plasmids encode a single transporter which has the ability to transport both glucose and galactose and may serve both functions in B. abortus. Rest \& Robertson (1974) noted that both galactose and glucose stimulated efflux of labelled glucose from $B$. abortus cells. The $E$. coli galP transporter also carries both glucose and galactose, though the physiological significance of its ability to transport glucose is not clear since it is not induced by glucose. There is no evidence for any other genes involved in glucose metabolism in the area sequenced, so the genes are not clustered in Brucella as they are, for instance, in Zymomonas mobilis (Barnell et al., 1990) and Pseudomonas aeruginosa (Cuskey et al., 1985).

The B. abortus glucose/galactose transporter and the $E$. coli fucP transporter are similar enough to be considered homologous, and thus members of a family. From structural and functional considerations, they should belong to the MFS, but fucP was not previously considered a member because it was not clearly homologous to any other members of the MFS (Griffith et al., 1992; Marger \& Saier, 1993). Comparing the gluP-fucP family against the rest of the MFS gives a significance score of $7 \cdot 3$, using the alignment from which the phylogeny was calculated. In comparison, the other families gave scores of 6.4-9.7 for the same alignment. This family appears to be a little closer to family 3 , the di- and tricarboxylate carriers, but the order of branching is not very well defined from the data available.

The sequence suggested that pRE184 might carry the B. abortus his G gene, and this possibility was confirmed by its ability to complement E. coli hisG. From the orientation of the gene, it is clearly not arranged in an operon like the E. coli one, which begins with his $G$ at the promoter end (Winkler, 1987).

\section{ACKNOWLEDGEMENTS}

Thanks to Ms Debra A. Phelps, Ms Roushan Samad and Mr Mike Byrum for competent technical assistance and to Ms Kimberly Miller for starting the sequencing. The OSU Recombinant DNA/Protein Resource Facility did much of the sequencing and synthesized the oligonucleotides used. Dr U. K. Melcher provided valuable advice on determining phylogenies and he and Dr Jacque Fletcher provided valuable comments on the manuscript. We thank Drs Pieter Postma and R. D. Porter for generous gifts of strains. This work was supported by USDA grants USDA-86-CRC-1-2209 and USDA-ARS \#58-5114-9-1008 and the Oklahoma Agricultural Experiment Station. This publication has been approved by the Director, Oklahoma Agricultural Experiment Station.

\section{REFERENCES}

Allardet-Servent, A., Bourg, G., Ramuz, M., Pages, M., Bellis, M. \& Roizis, G. (1988). DNA polymorphism in strains of the genus Brucella. J Bacteriol 170, 4603-4607.

Altschul, S. F., Gish, W., Miller, W., Myers, E. W. \& Lipman, D. J. (1990). Basic local alignment search tool. J Mol Biol 215, 403-410.

Barnell, W., Yi, K. \& Conway, T. (1990). Sequence and genetic organization of a Zymomonas mobilis gene cluster that encodes several enzymes of glucose metabolism. $J$ Bacteriol 172, $7227-7240$. 
Bullock, W. O., Fernandez, J. M. \& Short, J. M. (1987). XL1-Blue: a high efficiency plasmid transforming recA Escherichia coli strain with $\beta$-galactosidase selection. Biotechniques 68, 376-379.

Carter, M. \& Milton, I. (1993). An inexpensive and simple method for DNA purifications on silica particles. Nucleic Acids Res 21, 1044.

Chung, C. T., Niemela, S. L. \& Miller, R. H. (1989). One-step preparation of competent Escherichia coli: transformation and storage of bacterial cells in the same solution. Proc Natl Acad Sci USA 86, 2172-2175.

Clark, L. \& Carbon, J. (1979). Selection of specific clones from colony banks by suppression or complementation tests. Methods Enzymol 68, 396-408.

Csonka, L. N. \& Clark, A. J. (1979). Deletions generated by the transposon Tn10 in the $s r l$ recA region of the Escherichia coli $\mathrm{K} 12$ chromosome. Genetics 93, 321-343.

Cuskey, S. M., Wolff, J. A., Phibbs, P. V., Jr \& Olsen, R. H. (1985). Cloning of genes specifying carbohydrate catabolism in Pseudomonas aeruginosa and Pseudomonas putida. J Bacteriol 162, 865-871.

Dayhoff, M. O., Barker, W. C. \& Hunt, L. T. (1983). Establishing homologies in protein sequences. Methods Enzymol 91, 524-545.

Devereux, J., Haeberli, P. \& Smithies, O. (1984). A comprehensive set of sequence analysis programs for the VAX. Nucleic Acids Res 12, 387-395.

Essenberg, R. C. \& Sharma, Y. K. (1993). Cloning of genes for proline and leucine biosynthesis from Brucella abortus by functional complementation in Escherichia coli. J Gen Microbiol 139, 87-93.

Felsenstein, J. (1989). PHYLIP - phylogeny inference package. Cladistics 5, 164-166.

Griffith, J., Baker, M., Rouch, D., Page, M., Skurray, R., Paulsen, I., Chater, K., Baldwin, S. \& Henderson, P. (1992). Membrane transport proteins: implications of sequence comparisons. Curr Opin Cell Biol 4, 684-695.

Hanahan, D. (1983). Studies on transformation of Escherichia coli with plasmids. J Mol Biol 166, 557-580.

Heinrich, P. (1988). Construction of nested deletions for DNA sequencing. In Current Protocols in Molecular Biology I, Supplement 2, pp. 7.3.1-7.3.20. Edited by F. M. Ausubel, R. Brent, R. E. Kingston, D. D. Moore, J. G. Seidman, J. A. Smith \& K. Struhl. New York: John Wiley.

Kay, W. W. \& Kornberg, H. L. (1971). The uptake of $\mathrm{C}_{4}$ dicarboxylic acids by Escherichia coli. Eur J Biochem 18, 274-281.

Krogh, A., Mian, I. \& Haussler, D. (1994). A hidden Markov model that finds genes in E. coli DNA. Report No. UCSC-CRL-93-33, University of California at Santa Cruz.
Luria, S. E. \& Burrous, J.W. (1957). Hybridization between Escherichia coli and Shigella. J Bacteriol 97, 461-476.

Maloy, S. R. \& Nunn, W. D. (1981). Selection for loss of tetracycline resistance by Escherichia coli. J Bacteriol 145, 1110-1112.

Marger, M. \& Saier, M., Jr (1993). A major superfamily of transmembrane facilitators that catalyse uniport, symport and antiport. Trends Biochem Sci 18, 13-20.

McCullough, N. \& Beal, G. (1951). Growth and manometric studies on carbohydrate utilization of Brucella. J Infect Dis 89, 266-271.

Melcher, U. (1993). HIV-1 proteinase as structural model of intercellular transport proteins of plant viruses. J Theor Biol 162, 61-74.

Miller, J. H. (1972). Experiments in Molecular Genetics. Cold Spring Harbor, NY: Cold Spring Harbor Laboratory.

Pearson, W. R. \& Lipman, D. J. (1988). Improved tools for biological sequence comparison. Proc Natl Acad Sci USA 85, 2444-2448.

Persson, B. \& Argos, P. (1994). Prediction of transmembrane segments in proteins utilising multiple sequence alignments. J Mol Biol 237, 182-192.

Rest, R. F. \& Robertson, D. C. (1974). Glucose transport in Brucella abortus. J Bacteriol 118, 250-258.

Robertson, D. C. \& McCullough, W. G. (1968a). The glucose catabolism of the genus Brucella. I. Evaluation of pathways. Arch Biochem Biophys 127, 263-273.

Robertson, D. C. \& McCullough, W. G. (1968b). The glucose catabolism of the genus Brucella. II. Cell-free studies with $B$. abortus (S-19). Arch Biochem Biophys 127, 445-456.

Sanger, F., Nicklen, S. \& Coulson, A. (1977). DNA sequencing with chain-terminating inhibitors. Proc Natl Acad Sci USA 74, 5463-5467.

Schleicher \& Schuell (1987). Transfer and Immobilization of Nucleic Acids to Schleicher \& Schuell Solid Supports. Keene, NH: Schleicher \& Schuell.

Southern, E. M. (1975). Detection of specific sequences among DNA fragments separated by gel electrophoresis. $J \mathrm{Mol} \mathrm{Biol} \mathrm{98,}$ 503-517.

Winkler, M. E. (1987). Biosynthesis of histidine. In Escherichia coli and Salmonella typhimurium. Cellular and Molecular Biology, pp. 395-411. Edited by F. C. Neidhardt. Washington, DC: American Society for Microbiology.

Received 25 July 1996; revised 6 January 1997; accepted 15 January 1997. 